\title{
Adaptation and validation of the Maslach Burnout Inventory-Human Services Survey in Cali, Colombia*
}

\author{
Leonor Córdoba, PhD", Julián Andrés Tamayo, Stat², \\ Mónica Alexandra González, Psychol ${ }^{3}$, María Isabel Martínez, Psychol ${ }^{2}$, \\ Alejandra Rosales, Psychol ${ }^{4}$, Sofia Helena Barbato, EnF ${ }^{5}$
}

\section{SUMMARY}

Objective: The objective of this study was to establish the psychometric properties of reliability and validity of the «Maslach Burnout Inventory-Human Services Survey» (MBI-HSS).

Methods: The work was conducted by a process of translation and back-translation of the original instrument, instrument adaptation, translation and adaptation of the application manual, pilot study, and implementation of the adapted version of the instrument with 314 health professionals in Cali, according to the guidelines of the International Test Commission (ITC).

Results: The results showed that the scale has good internal consistency $(\mathrm{a}=0.767)$; however, the dimension of «depersonalization» has the lowest internal consistency $(\mathrm{a}=0.518)$. Regarding validity, in comparing between the factor structure of the modified scale with the original version, we identified that the size of the validated version largely coincides with that of the original version; in the dimension of emotional fatigue, item 6 is excluded because it will be part of the depersonalization scale, items 15 and 21 were also excluded given their poor discriminatory ability.

Conclusion: It is necessary to overcome the stability problems of the MBI-HSS depersonalization subscale in health professionals and reformulate the response options to make them more understandable for professionals within the Colombian context.

Keywords: Burnout; Adaptation; Reliability; Validity; Maslach Burnout Inventory-Human Services Survey (MBI-HSS).

Colomb Med. 2011; 42: 286-93

\begin{abstract}
Adaptación y validación del Inventario Maslach para el Desgaste Profesional-Encuesta para los Servicios de Salud en Cali, Colombia
\end{abstract}

\section{RESUMEN}

Objetivo: El objetivo del presente estudio fue establecer las propiedades psicométricas de fiabilidad y validez del «Inventario Maslach para el Desgaste Profesional-Encuesta para los Servicios de Salud» (Maslach Burnout InventoryHuman Services Survey (MBI-HSS).

Métodos: Se llevó a cabo un proceso de traducción-retrotraducción del instrumento original, adaptación del instrumento, traducción y adaptación del manual de aplicación, estudio piloto y aplicación de la versión adaptada del instrumento a 314 profesionales de la salud de Cali, de acuerdo con los lineamientos de la Comisión Internacional de Test (ITC).

* Research funded by Pontificia Universidad Javeriana, Cali, Colombia. Research Group on Psychology, Health, and Quality of Life, and the Fundación Clínica Valle del Lili, Cali, Colombia.

1. Director, Master in Psychology Health and Disability, Faculty of Psychology, Universidad de La Sabana, Bogotá, Colombia. e-mail: lcorand@gmail.com

2. Research Group on Psychology, Health and Quality of Life. Research Assistant, Pontificia Universidad Javeriana, Cali, Colombia. e-mail: juliandt@univalle.edu.co mimartinez@javerianacali.edu.co

3. Research Group on Health and Quality of Life, Pontificia Universidad Javeriana, Cali, Colombia. e-mail:monicagonzalez15@hotmail.es

4. Research Group on Psychology, Health and Quality of Life, Pontificia Universidad Javeriana, Cali, Colombia. e-mail: arosales@javerianacali.edu.co

5. Coordinator Occupational Health, Fundación Clínica Valle del Lili, Cali, Colombia. e-mail: sbarbato@fcvl.org Received for publication April 4, 2010 Accepted for publication December 21, 2010 
Resultados: Los resultados mostraron que la escala posee una buena consistencia interna $(\alpha=0.767)$. Sin embargo, la dimensión «despersonalización» tiene la menor consistencia interna $(\alpha=0.518)$. En relación con la validez, al comparar la estructura factorial de la escala adaptada con la versión original, se identificó que las dimensiones de la versión validada coinciden en buena medida con las de la versión original; en la dimensión cansancio emocional se excluye el punto 6 que hará parte de la dimensión despersonalización y se eliminan los puntos 15 y 21 por su poca capacidad discriminativa.

Conclusión: Es necesario superar los problemas de estabilidad de la subescala de despersonalización para el MBIHSS en profesionales de la salud, así como reformular las opciones de respuesta para que sean más comprensibles para los profesionales en el contexto de Colombia.

Palabras clave: Desgaste profesional; Adaptación; Fiabilidad; Validez; Inventario Maslach para el Desgaste Profesional (MBI-HSS).

\section{Colomb Med. 2011; 42: 286-93}

Changes in Colombian legislation regarding healthcare policies require greater actions geared at humanizing and within that humanizing, the healthcare professional-patient relationship constitutes a fundamental aspect that must be preserved, which is why foreseeing the high levels of stress affecting these professionals, has become a priority task, leading to research that provides relevant information on the implications and consequences of these types of responses to inadequate working conditions. The high levels of stress (emotional tension) have become a pathology that accompanies much of the working population. It is frequently found that said pathology ends up turning into what is known as professional Burnout syndrome (PBS), also called work-burnout syndrome (WBS) or as it is known internationally «Burnout syndrome» (BS).

The World Health Organization (WHO) considers the WBS a labor-related disease in diverse countries, given that it affects individuals enduring it both physically and psychologically. It is defined as a manifestation of chronic stress, which is originated by a deficient adaptation to environmental demands, specifically, those from the job environment, producing alterations in the quality of life of the person afflicted with it and -above all- in the services provided by the individual. It is common to find in research on this phenomenon ${ }^{1-3}$ that the population found within this range of vulnerability are mainly healthcare professionals, nurses, and physicians in whom BS significantly impacts on the exercise of their clinical duties, bringing on manifestations of phenomena like loss of interest for activities undertaken, apathetic behavior with patients, which could finally lead to a loss of human sense against the perception of pain and suffering of the individuals seeking healthcare services, generating inconformity or indisposition by users of healthcare services and, at the same time, by the work team.

The professional burnout syndrome has been conceptualized by various researchers in different contexts like schools, hospitals, and prisons ${ }^{3-6}$ and associated to diverse variables like sex, work schedule, job environment, professional trajectory, responsibility for the lives of others, and contact with suffering and death ${ }^{7-12}$, but it was Freudenberger ${ }^{13}$, who coined the term, and Maslach $^{14}$ by studying the emotional responses of professionals in healthcare services, described it as a tridimensional syndrome comprising: high emotional fatigue, low personal fulfillment, and depersonalization. Maslach et al. ${ }^{15}$, conceptualize Burnout as emotional fatigue leading to a loss of motivation and tending progress to feelings of inadequacy and failure.

Because of the implications this disease has upon the personal and professional lives of individuals enduring it, and directly upon the care of their patients, it is fundamentally important to study this phenomenon; especially, to learn of its development within our context and how it affects individuals and organizations dedicated to healthcare services and to provide services to; thus, be able to offer intervention proposals to prevent new cases and improve working conditions and the quality of life of workers at greater risk of suffering this syndrome.

An initial step in seeking to prevent pathologies with numerous social implications is to evaluate the prevalence of the syndrome with a reliable and valid instrument, adapted to our context. For this reason, this study was conducted by selecting the Maslach Burnout Inventory-Human Services Survey (MBI-HSS) ${ }^{16}$, given that it is considered one of the most widely used instruments by researchers in the international ${ }^{14,17}$ and national ${ }^{18-22}$ contexts; nevertheless, scientific literature on the topic also takes into account criticism against the 
instrument, especially that having to do with its demensionality ${ }^{23}$.

Regarding the psychometric properties of the MBIHSS, there are several studies aimed at its determination, for example, in Spain, García et al. ${ }^{17}$ conducted a factorial study on the Spanish version of the MBI-HSS scale, using a Varimax rotation, which presented five factors with values greater than one, finding reliability values in the sub-scales, which permit observing that emotional fatigue is the strongest sub-scale (0.88), followed by personal fulfillment (0.81), and lastly, depersonalization (0.79). Likewise, in Chile, research was carried out to verify the factorial validity of MBIHSS with a sample of social workers ${ }^{24}$. The findings in that work suggest that the test presented a tri-factorial structure, verifying the proposal of the original authors. Regarding the sub-scales, the one with the greatest factorial weight was emotional fatigue, followed by personal fulfillment and the sub-scale with the least weight was depersonalization. It is worth mentioning that in the review of the scientific literature no studies were found on this theme.

With this frame of reference, and bearing in mind that the adaptation and validation of already existing instruments, it is a usual procedure in assessing psychological constructs like stress, and most specifically professional Burnout (Burnout), due to factors like lower investment of economic resources, time, and human work, the objective of this study was to adapt and validate the MBI-HSS with a sample of healthcare professionals in a hospital institution in the city of Cali, Colombia, according to guidelines from the International Test Commission.

\section{METHODS}

This was an instrumental work. Instrumental studies are those in charge of designing or adapting tests.

Participants. The sample was comprised of 314 healthcare professionals working at a hospital institution in the city of Cali, who were given the MBI-HSS ${ }^{16}$ adapted for the Colombian context.

As inclusion criteria, it was established that they should be healthcare professionals with direct and permanent contact with patients, ranging in age from 20 to 57 years, for the purpose of excluding professionals with a short professional trajectory in this type of work or in the process of retiring. We also excluded those professionals who were undergoing psychiatric treatment or who were in mourning, because these factors are considered confusing for the professional burnout syndrome. The sample size was defined from the criterion of the number de items making up the scale and it was calculated from a minimum of 10 participants per each item of the instrument to perform the factorial analysis.

The sample selection was carried out from a stratified random sampling in the 11 medical units in the hospital institution. The sample included 59 physicians $(18.8 \%)$ and 255 professional healthcare workers $(81.2 \%)$, among which there were nurses, nursing assistants, physiotherapists, and instrumentalists. Of the professionals selected, $27.4 \%$ were males and $72.6 \%$ were females. The mean age of the participants was 32.36 years with a typical deviation of 8.83 years (ranging from 20 to 57 years). The average working time for the professionals' main job functions was 52.32 hours per week ( $D T=10.76$ hours per week). The mean for years on the job in the institution was 5.98 years $(D T=4.73$ years). A total of $95.2 \%$ of the participants defined themselves as religious. Regarding marital status, $39.2 \%$ were single and a similar percentage $(37.3 \%)$ was married, and $6.4 \%$ were divorced. The level of education with the highest percentage $(50.0 \%)$ was technical/ technological training, $25.8 \%$ were professionals, and only $0.3 \%$ of the participants had a PhD.

Instrument. The measurement instrument used in this research was the MBI-HSS ${ }^{16}$, adapted for the population of Cali by the authors doing this work. The adaptation process consisted in translating the original instrument into Spanish and then it was translated back into its original language to note correspondence in the languages; thereafter, expert judges evaluated the level of pertinence for each item constituting the scale.

The MBI-HSS is made up of 22 items elaborated for healthcare professionals; each item is an affirmation on the professionals' feelings and attitudes toward their work and their patients. It presents a Likert-type response format with the options of: never (0), a few times per year or less (1), once a month or less (2), a few times per month (3), once per week (4), a few times per week (5), and every day (6). It comprises three sub-scales: the first is composed of nine items $(1,2,3,5,6,8,13,14,16$, ) corresponding to emotional fatigue $(\mathrm{EF})$ and including characteristics like 
physical wear, exhaustion, fatigue, and loss of energy, showing a combination between the physical and the mental. The second, composed of five items $(5,10,11,15$, and 22), is catalogued as depersonalization (DP), manifesting negative aspects of the responses and attitudes involving other individuals, but mainly work mates. Irritability and loss of motivation are also presented. The third sub-scale corresponds to personal fulfillment (PF), which contains eight items $(4,7,9,12,17,18,19,21)$, which shows typical negative responses aimed at the respondent and the workitself. These responses are related to depression, low morale, avoidance of interpersonal and professional relationships, low productivity, inability to withstand pressure, and poor self esteem.

Analysis of results. For the statistical analysis of the data, we used the SPSS statistical package version 15 for Windows and the AMOS 16 complement. First, the characterization of the sample was done by using descriptive statistics. The following analyses were based on the psychometric properties of the MBI-HSS. The discrimination or homogeneity indices were calculated for each item via the corrected item-test correlation, which permitted evaluating the discriminatory power of each item and the relationship with its respective dimension. Then, the validity of the scale construct was examined via the confirming factorial analysis with the model of structural equations. Finally, the reliability of the scale was evaluated through Cronbach's Alphas coefficient for the sub-scales and the total scale.

\section{RESULTS}

Analysis of items. The first step for the MBI-HSS analysis was to study the behavior of the items. Selection of each item was based on the capacity to show differences in the professional burnout syndrome among healthcare professionals. The discriminatory analysis of the items was first performed via the item-total correlation. The highest correlation was presented by item 8 («I feel burnt out by my work»), whose index indicates that the relationship between this item and the remaining ones is considerable $(\mathrm{r}=0.60)$. The lowest correlation was obtained by item 15 («I am really not concerned with what happens to some of my patients»); this shows that it barely has a relationship with the rest of the items in the scale $(r=0.03)$. Seven of the 22 items $(31.8 \%)$ have a low correlation $(<0.20)$ with the scale total, especially items 4 («I easily understand how my patients feel») and 9 («I feel I positively influence the lives of other individuals through my work») with correlation levels of 0.05 and 0.10 , respectively. Most of the items, according to the discrimination, present an acceptable level and the internal consistency of the total scale is very similar with the elimination of any item.

Table 1 shows this same type of analysis by using the sub-scales originally proposed by the MBI-HSS. For the first dimension (emotional fatigue), all the correlations of the items are acceptable. This characteristic is not present in the second dimension (DP), given that items 15 and 22 only have a relationship with the rest of the items in this dimension. Regarding the last dimension (PF), four of its items have a correlation close to 0.20 with the rest. It is notable that the correlations manage to be higher, but there are still items with low discriminatory capacity. The reliability of the first and last dimensions when eliminating items one by one is maintained between 0.78 and 0.83 , and 0.47 and 0.57 , respectively; from this criterion, the items comprising each sub-scale may be maintained.

According to this, it may be said that the behavior of the MBI-HSS items reveal certain inconsistency when analyzing the relationship of some of them with the rest. In this sense, the low correlation presented by the items suggests the need to revise them.

\section{Validity of construct}

Factorial structure: first confirming analysis. To contrast to what degree of fit our data reproduce the original distribution offered in the factorial solution of the manual (EF, DP, and PF) we used the technique of confirming factorial analysis. This analysis permits finding tests for the internal validity of the questionnaire. Based on the MBI-HSS manual, the independence of the factors is assumed. To solve the lack of multivariate normality, we used the estimation method of unweighted least squares for the structural equations model. We will use the partial fit indices like RMR and RMSEA, due to the noncompliance of the suppositions.

In conducting the confirmatory factor analysis, the model yielded an unsatisfactory adjustment in view of the adjustment rate RMR (0.177). This means that the model assumption does not fit the data found for this sample, for this reason it is necessary to explore other models.

Factorial structure: exploratory factorial analysis. 
Table 1

Discrimination analysis of the items of the MBI-HSS sub-scales

\begin{tabular}{lrcc}
\hline Dimension & Item & $\begin{array}{c}\text { Corrected item-sub-scale } \\
\text { correlation }\end{array}$ & $\begin{array}{c}\text { Cronbach's Alpha if the item } \\
\text { is eliminated }\end{array}$ \\
\hline \multirow{5}{*}{ Emotional fatigue } & 1 & & \\
& 2 & 0.63 & 0.79 \\
& 3 & 0.57 & 0.80 \\
& 6 & 0.63 & 0.79 \\
& 13 & 0.28 & 0.83 \\
& 14 & 0.72 & 0.78 \\
Depersonalization & 16 & 0.38 & 0.82 \\
& 20 & 0.60 & 0.80 \\
& 5 & 0.46 & 0.81 \\
& 10 & 0.43 & 0.82 \\
& 11 & 0.22 & 0.26 \\
& 15 & 0.25 & 0.19 \\
& 22 & 0.23 & 0.22 \\
& 4 & 0.05 & 0.36 \\
& 7 & 0.09 & 0.33 \\
\hline 9 & 0.20 & 0.55 \\
& 9 & 0.34 & 0.50 \\
& 12 & 0.22 & 0.54 \\
& 17 & 0.31 & 0.51 \\
& 18 & 0.27 & 0.53 \\
& 19 & 0.43 & 0.47 \\
& 21 & 0.24 & 0.54 \\
& 0.20 & 0.57 \\
\hline
\end{tabular}

After inquiring on the initial structure, we conducted an exploratory factorial analysis. The factor extraction method used was that of the main components with Varimax rotation. Considering the sample size $(n=314)$, the criterion was to assign an item to all factors with a factorial weight greater than 0.3 . Table 2 shows the factorial matrix and the percentage of variance explained for each of the factors. As noted, we obtained seven factors with values greater than one, which explained $55.4 \%$ of the total variance. Seven of the nine items from the dimension measuring $\mathrm{EF}$ were grouped in factor 1 (items 1, 2, 3, 8, 13,14, and 20), item 16 has its second best load in this factor. Factor 2 grouped items 7,9 , and 12, which measure PF, but besides that item 18 has its second factorial load in this factor, which also deals with PF. Factor 3 is composed of four items that measure different constructs. In factor 4 the other items
$(4,17,18$, and 19) are grouped, which measure PF; although this last item has its greatest load in factor 6 , it also has a considerable load in this factor. Only two items were grouped in factor 5 evaluating DP. Lastly, factors 6 and 7 grouped the three remaining items. It seems that factors 2 and 4 as a whole would explain the dimension of PF and factors 5 and 7 grouped three of the five items of DP.

When comparing this factorial structure with that originally found, we found some similarities in the dimensions, even though the number of these dimensions is different in both versions. To accomplish a factorial structure consistent with the original version and the data found for this sample, we managed to summarize all the data into a new factorial structure, which is presented in Table 3. Given that items 15 and 21 did not manage to get represented in the factorial structure, 
Table 2

Factorial matrix $(n=314)$

\begin{tabular}{|c|c|c|c|c|c|c|c|}
\hline Items & 1 & 2 & 3 & 4 & 5 & 6 & 7 \\
\hline 1 & 0.74 & & & & & & \\
\hline 2 & 0.72 & & & & & & \\
\hline 3 & 0.78 & & & & & & \\
\hline 8 & 0.80 & & & & & & \\
\hline 13 & 0.37 & & & & 0.34 & & \\
\hline 14 & 0.72 & & & & & & \\
\hline 20 & 0.57 & & & & & 0.43 & \\
\hline 7 & & 0.70 & & & & & \\
\hline 9 & & 0.55 & & & & & \\
\hline 12 & & 0.62 & & & & & \\
\hline 5 & & & 0.62 & & & & \\
\hline 6 & & & 0.66 & & & & \\
\hline 16 & 0.40 & & 0.44 & & & & \\
\hline 22 & & & 0.62 & & & & \\
\hline 4 & & & & 0.65 & & & \\
\hline 17 & & & & 0.60 & & & \\
\hline 18 & & 0.38 & & 0.65 & & & \\
\hline 10 & & & & 0.31 & 0.65 & & \\
\hline 11 & & & & & 0.70 & & \\
\hline 19 & & & & 0,42 & & 0.50 & 0.31 \\
\hline 21 & & & & & & 0.76 & \\
\hline 15 & & & & & & & 0.85 \\
\hline Own value & 4.171 & 2.057 & 1.454 & 1.234 & 1.146 & 1.068 & 1.047 \\
\hline Explained variance & 18,959 & 9.351 & 6.608 & 5.61 & 5.209 & 4.856 & 4.761 \\
\hline
\end{tabular}

Table 3

New structure of the MBI-HSS

\begin{tabular}{clcc}
\hline Factor & MBI-HSS dimension & Item & $\mathbf{N}^{\circ}$ of items \\
\hline 1 & Emotional fatigue & $1,2,3,8,13,14,16,20$ & 8 \\
2 & Personal fulfillment & $4,7,9,12,17,18,19$ & 7 \\
3 & Depersonalization & $5,6,10,11,22$ & 5 \\
\hline
\end{tabular}

they will be excluded from the final scale.

Factorial structure: second confirming analysis. In a second step, we again performed a confirmatory factor analysis for the three factors formed from the structure found. The goodness of fit statistics for the new hypothesized factor structure indicate good fit of the model to the data: although the chi-square value was high $\left(\chi^{2}=286,522\right.$, we can not base our conclusions on this statistic because the data distribution does not conform to the multivariate normal distribution), the RMSEA $=0.047$ does not exceed the critical threshold of 0.10 and its limits of the confidence level of $90 \%$ are 
Table 4

Internal consistency

\begin{tabular}{lccccc}
\hline & \multicolumn{2}{c}{$\mathbf{N}^{\circ}$ of items } & \multicolumn{2}{c}{ Correlation range } & Correlation mean Cronbach's alpha \\
\hline Maslach Burnot Inventory (MBI) & 20 & 0.04 & 0.63 & 0.32 & 0.77 \\
Emotional fatigue & 8 & 0.39 & 0.73 & 0.55 & 0.83 \\
Personal fulfillment & 7 & 0.19 & 0.49 & 0.29 & 0.57 \\
Depersonalization & 5 & 0.14 & 0.30 & 0.23 & 0.52 \\
\hline
\end{tabular}

within the acceptable range [0037, 0056]; also, the magnitude of the RMR rate $=0071$ standard is not excessive. Accordingly, we do not reject the hypothesis of this model and believe that these three factors to assess the Burnout syndrome are appropriate.

Reliability analysis. We examined the reliability of the sub-scales found, through their internal consistency with Cronbach's Alpha index. Table 4 summarizes these values. It can be seen that the internal consistency of the DP sub-scale was the lowest and that it is inadequate (0.52), as was the sub-scale for PF (0.57). While the sub-scale for EF from the new MBI-HSS structure presented very good internal consistency.

\section{DISCUSSION}

The process of adapting and validating instruments that assess diverse psychosocial phenomena for the Colombian context constitutes a challenge for psychology professionals, particularly, when the use of the instrument is generalized and, occasionally this is done indiscriminately, without bearing in mind the restrictions for its use, given that it is a foreign instrument or an adaptation of such, in countries that although sharing the same language, differ from the Colombian culture in various aspects. The use of the instruments is in function of the demands for diagnosis and intervention, unaware to a certain extent of their psychometric properties and the conditions of practical utility, with the conceived consequences of wrongful conclusions on research, over or under diagnoses, and the acquisition of very poor elements for the intervention. An example of this is constituted by the professional burnout syndrome (internationally known as Burnout).

For this reason, this study seeks to contribute to researchers and professionals working in mental health, so they can have sufficient judgment elements in making decisions about the election of a reliable and valid instrument with sufficient practical utility, which permits them to assess, diagnose and monitor the professional burnout syndrome in human service professionals, due to the implications this has on the mental health of those enduring it, and in general terms, the impact on health services.

The results reveal that the MBI-HSS, in general, presents an adequate internal consistency $(\alpha=0.767)$ so as to be used in assessing the professional burnout syndrome in healthcare professionals in Cali; however, it is worth noting that the DP and PF sub-scales present the lowest internal consistencies $(\alpha=0.51$ and 0.57 , respectively). On the contrary, it may be said that the soundest sub-scale and where there is the highest reliability is that referring to $\mathrm{EF}(\alpha=0.83)$; results contrary to those reported by Albadalejo et al. ${ }^{11}$ who obtained values of 0.9089 for EF; 0.7532 for DP, and 0.8133 for PF. In the same direction, the results of the psychometric analyses conducted on the original instrument, reveal that the reliability coefficient for the sub-scales was 0.90 for EF or exhaustion, 0.79 for DP, and 0.71 for low PF.

Additionally, from the results obtained in this study, we propose the elimination of items 15 («I am really not concerned with what happens to some of my patients») and 21 ( «In my work Imanage many emotional problems calmly»), given that they present low correlations with relation to the total scale ( 0.027 and 0.160 , respectively) and the sub-scales ( 0.05 and 0.203 , respectively) and they are seen as factorially complex items making their interpretation difficult.

It may also be stated that, although this MBI-HSS adaptation and validation presents weaknesses (specifically in the DP dimension), the results obtained support the three-dimension structure of the original scale. Some of these weaknesses are due more to the incoherencies in the response options of the items. 
Hence, MBI-HSS validation for this context fulfills sufficient validity and reliability requirements so as to be used in the preliminary estimation of the professional burnout syndrome in general and not by sub-scales. Nevertheless, we must bear in mind that the results can be influenced by these weaknesses, thus, a new assessment of the instrument is recommended with the solution of the item response options.

Lastly, it is convenient to highlight on preventing the professional burnout syndrome and its implications within our context. The working conditions of a good number of healthcare professionals like lack of equipment, long work days, unsatisfactory salaries, and low personal achievement, among others, constitute risk factors that impact upon on the emotional health of these professionals and, obviously, transcend to the care they offer those consulting with them, drastically influencing on the humanization of healthcare. Among the possible solutions offered for this problem ${ }^{25}$, we should indicate changes in labor policies in healthcare institutions, with that having to do with the number of individuals health professionals must care for during their shift, the duration of the work shifts and the rest periods, and the development of competencies to encounter work stress, among others.

Conflict of interest. None of the authors has conflicts of interest related to this study.

\section{REFERENCES}

1. Carretero N, Roldán M, Gil-Monte P. Algunos procesos psicosociales sobre el síndrome de quemarse por el trabajo (Burnout) en profesionales de enfermería. Ansiedad y Estres. 2005; 11: 281-90.

2. Quiceno J, Vinaccia S. Burnout: Síndrome de quemarse en el trabajo (SQT). Acta Colomb Psicol. 2007; 10: 117-25.

3. Viloria H, Paredes M. Estudio del síndrome de Burnout o professional burnout en los profesores de la Universidad de los Andes. EDUCERE Rev Venezol Edu. 2002; 6: 29-36.

4. Naudé J, Rothmann S. The Validation of the Maslach Burnout Inventory-Human Service survey for emergency medical technicians in Gauteng. SA J Ind Pshych. 2004; 30: 21-28.

5. Topa G, Lisbona A, Palaci F, Morales J. Determinantes específicos de la Satisfacción laboral, el burnout y sus consecuencias para la salud: Un estudio exploratorio con funcionarios de prisiones. Int J Pshychol Pshycol Ther. 2005; 5: 71-81.

6. Dickinson B, González-Salinas C, Fernández MA, Palomeque RP, González-Quintanilla E, et al. Burnout syndrome among Mexican primary care physicians. Arch Med Fam. 2007; 9: 75-9.
7. Pando M, Aranda C, Aldrete MG, Flores EE, Pozos E. Factores psicosociales y burnout en docentes del centro universitario de ciencias de la salud. Invest Salud. 2006; 8: 73-7.

8. Álvarez A, Arce M, Barrios A, Sánchez A. Síndrome de Burnout en médicos de hospitales públicos de la ciudad de Corrientes. Rev Postgrado Cat Med. 2005; 141: 27-30.

9. Marrero M, Grau J. Síndrome de Burnout en médicos que trabajan en unidades de cuidados intensivos neonatales. Psicol Salud. 2005; 1: 25-32.

10. Martín S, Arfken C, Balon R. Comparison of exhaustion between medical residents before and later of the putting in practice of the limits of hours of work. Acad Psychiatr. 2006; 4: $52-5$.

11. Albaladejo R, Villanueva R, Ortega P, Astasio P, Calle M, Domínguez V. Síndrome de Burnout en el personal de enfermería de un hospital de Madrid. Rev Esp Salud Publica. 2004; 78: 505-16.

12. Viseer M, Smets E, Oort F, Haes H. Stress, satisfaction and burnout among Dutch medical specialist. CMAJ. 2003; 168: 271-5.

13. Freudenberger, H. Staff burnout. J Soc Issues. 1974; 30: 159-65.

14. Maslach C. Burned-out. Human Behavior. 1976; 5: 16-22.

15. Maslach C, Schaufeli W, Leiter M. Job burnout. Ann Rev Psychiatr. 2001; 59: 379-422.

16. Maslach C, Jackson, S. Maslach Burnout Inventory-Human Services Survey (MBI-HSS). En: Maslach C, Jackson, S. Leiter M (eds.). Maslach Burnout Inventory Manual. Mountain View: Consulting Pschologists Press; 1996.

17. García J, Herrero S, León J. Validez factorial del Maslach Burnout Inventory (MBI) en una muestra de trabajadores del Hospital psiquiátrico penitenciario de Sevilla. Apuntes Psicol. 2007; 25: 157-74.

18. Correal M, Posada M, Pérez L. El síndrome de Burnout: Conceptualización, evaluación y prevención [Trabajo de grado]. Bogotá: Universidad Católica de Colombia; 2000.

19. Guevara CA, Henao DP, Herrera JA. Síndrome de Burnout profesional en médicos internos y residentes. Hospital Universitario del Valle. Cali. Colomb Med. 2004; 35: 173-8.

20. Hernández P. Estudio descriptivo del síndrome de Burnout en el personal de salud en el hospital militar central. Act Colomb Psicol. 2001; 7: 71-83.

21. Vinacia S, Alvaran L. El síndrome de Burnout en una muestra de auxiliares de enfermería: Un estudio exploratorio. Universitas Psychol. 2004; 3: 35-45.

22. Rozo M. Evaluación del síndrome de estrés asistencial en los profesionales de la salud en una institución hospitalaria de III nivel en la ciudad de Bogotá. Sicología, avances en la disciplina. 2007; $1: 185-214$.

23. Ortega C, López F. El Burnout o síndrome de estar quemado en los profesionales sanitarios: revisión y perspectivas. IJCHP. 2004; 4: 31-60.

24. Manso JF. Estructura factorial structure del Maslach Burnout Inventory. Versión Human Services Survey en Chile. Rev Interam Psicol. 2006; 40: 15-8.

25. Tounsel D, Reising D. If the legislation it can be useful in reducing the exhaustion between nurses of the hospital: a normative analysis. J Nurs Law. 2005; 2: 89-95. 